\title{
Expression and Storage of Breastmilk Among Urban Mothers in Southern India: Knowledge, Attitude, and Practice (KAP) Cross-sectional Survey
}

Renuka K ( $\sim$ renukasenthil08@gmail.com )

Panimalar Medical College Hospital and Research Institute

Umadevi R

Bharath University

Muthathal Subramanian

Panimalar Medical College Hospital and Research Institute

\section{Research Article}

Keywords: Breastmilk, breastfeeding practices, human milk bank, breastmilk storage and expression

Posted Date: January 27th, 2022

DOl: https://doi.org/10.21203/rs.3.rs-1289136/v1

License: (c) (i) This work is licensed under a Creative Commons Attribution 4.0 International License.

Read Full License 


\section{Abstract}

Background: Breast milk is always the best milk for the baby. Despite the advantages, many mothers are not able to pursue breastfeeding for various reasons. Breast milk can be continued for the babies even in their mother's absence for a while by expressing and storing the breast milk.

Aims: To assess the knowledge, attitude, and practice regarding expression and storage of breast milk (EBM) among mothers.

Methods: A community-based descriptive cross-sectional study was conducted for 3 months in the urban field practice area, Chennai. A sample size of 400 was selected using the systematic random sampling technique. The information was gathered using a pre-tested, structured questionnaire, which was then analysed using SPSS Version 16.0 and presented using appropriate statistical methods.

Results: Out of 400 , only $7 \%$ of them had adequate knowledge regarding the expression and storage of breast milk. A positive attitude towards the expression and storage of breast milk was seen among $3 / 4^{\text {th }}$ ( $77 \%$ ) of them. But only $2 \%$ had good practices related to expression and storage of breast milk.

Conclusions: Overall, knowledge and practice regarding EBM were very low, but more mothers had a positive attitude towards EBM. As there is a positive attitude towards it, the practices can be improved if the mothers are trained continuously during the antenatal period.

\section{Introduction}

Breast milk is the best milk produced by the mother for the baby. Besides being safe and clean, it provides complete nutrition and also protects the infant from various life-threatening infections. Breast milk provides all the energy and nutrient requirements that infants need for survival during the first 6 months of life and provides about half of the nutrient and energy needs during the second half of the year. It is an effective way to ensure a child's health and survival. Above all, it is possible to administer the breast milk to the baby even in the mother's absence by pumping and storing the breast milk and using it as and when required.

Globally, only about $40 \%$ of infants are exclusively breastfed. It is said that about 820,000 children would be saved each year if breastfeeding practices were scaled up. WHO gives three recommendations regarding breastfeeding, i.e., to initiate breastfeeding within one hour of life, to give exclusive breastfeeding up to 6 months of life, and to continue breastfeeding up to 2 years of age and beyond along with proper weaning foods. ${ }^{[1]}$

In India, 25 million babies are born every year, of which 3.5 million are pre-term and 7.5 million are low birth weight babies. These pre-term and low-birth weight babies face problems with survival, mainly due to feeding problems. ${ }^{[2]}$ Often, direct breastfeeding is not possible for these babies, and the next alternative would be expressed breast milk. Breast milk is expressed for various reasons. Some babies 
may require extra milk as a top-up feed after breastfeeding, some babies may not suck well at the breast, mothers may return to work, and some women express milk on a regular basis to improve milk production.

It is a proven fact that providing adequate nutrition to these babies not only yields short-term dividends but also long-term benefits in the form of improved neurodevelopmental outcomes.

Despite the known and proven benefits, many mothers abandon breastfeeding either partially or completely due to lack of sufficient time, early return to work, or because they do not know the expression and storage techniques of breast milk.

Based on the foregoing, this study was conducted to determine the knowledge, attitude, and practice regarding expression and storage of breast milk (EBM) among mothers in the urban area of Kancheepuram District, Tamilnadu. This helps to ascertain the gaps existing in the study area and to plan appropriate corrective strategies.

\section{Material And Methods}

A community-based cross-sectional study was conducted in Anakaputhur, the urban field practice area attached to a medical college in Kanchipuram district, Tamilnadu. It has 18 wards with a population of 48,050 (males: 24,158; females: 23,892). This study was conducted for 3 months from November 2018 to January 2019 among mothers residing in the study area for 1 year or more. The sample size was calculated based on the study conducted by Prabu PM et al., in Maharashtra ${ }^{[3]}$ which reported the knowledge of expression and storage of breast milk among mothers was $64 \%$, the sample size was calculated at a $95 \%$ confidence interval and keeping the precision as 5 . After accounting $10 \%$ for nonresponse, the final sample size was estimated to be 368 which is rounded off to 400 . Systematic random sampling was used to identify the study participants. Sampling interval was calculated as follows: Total number of households in Anakaputhur $(N)=1851$, Sample size $(n)=400$, Sampling interval $=N / n=$ $1851 / 400=4.6$. Thus every 5 th household was selected for identifying a subject. If there was no eligible respondent in the selected household, the next house with the eligible study subject was selected. From that house, the next $5^{\text {th }}$ household was selected. This procedure was followed till the desired sample size was reached. Mothers having a child of 2 years of age and less than 2 years were included after obtaining the informed consent. Mothers with children more than 2 years of age, had child expired and who were not willing to participate in the study were excluded from the study.

Data were collected from the consented participants using a pre-tested, structured questionnaire by the investigator. The questionnaire consisted of details regarding the sociodemographic characteristics and the knowledge, attitude, and practice regarding breast milk expression and storage of breast milk. The three main outcome variables in this study were knowledge, attitude, and practice regarding the expression and storage of breast milk among the study participants. These variables are composite 
scores and each outcome was measured using answers given by the study participants to several sets of questions.

The content of the question for each outcome and how these outcomes were scored are summarized below.

\section{Knowledge of the study participants on expression and storage of breast milk (6 questions)}

Each component was given a score of 1 for correct response and 0 for an incorrect response/answer not known. The scores were then added to generate a total score of 6 maximum. If the total score obtained by a study participant is $\geq 3$ then the individual is categorized as having "adequate knowledge", otherwise the individual is categorized as having "inadequate knowledge".

\section{Attitude of the study participant on expression and storage of breast milk (10 questions)}

Each response consistent with a positive attitude towards expression and storage of breast milk was given a score of 1 and 0 for a response with a negative attitude. The total score (out of the maximum score of 10 ) was calculated by adding the scores to individual questions. If the total score exceeds $50 \%$ the participant is classified as having a positive attitude and if not the participant is classified as having a negative attitude.

\section{Practices towards expression and storage of breast milk (4 questions)}

Practices towards expression and storage of breast milk were assessed using the following components - whether the study participants have expressed breast milk and if so how did they express it manually or with the help of an instrument, whether they stored the breast milk before feeding it to the baby. Each response consistent with good practice was given a score of 1 and if otherwise a score of 0 . The composite score of each individual was categorized using the cut off of $50 \%$ with scores above the cut off as "good practice "and if otherwise as "poor practice"

The data were entered in Microsoft (M.S.) Excel and analysed using SPSS software version 16.0. The results were obtained by applying appropriate descriptive and analytical statistics.

Ethical Approval: The study proposal was approved by the Institutional Ethical Committee of Sree Balaji Medical College and Hospital. Informed written consent in local language was obtained from all study participants before administering the study questionnaire.

\section{Results}

A total of 400 eligible mothers participated in the study. About $50 \%$ of the study participants belonged to the age group of $26-30$ years. Majority of the study participants belonged to Hindu religion (82\%) and were married \& live with the spouse (97\%). Half of them were graduates (51.3\%) and employed (43.2\%). 
More than half (59\%) of the mothers belonged to middle class and upper middle class as per Modified BG Prasad socioeconomic classification. ${ }^{[4]}$ (Table1).

Only $39 \%$ of the mothers had heard about the expression of breast milk. Overall, only $7 \%$ of the study subjects had adequate knowledge regarding expression and storage of breast milk. (Table 2)

Most of them felt that breast milk fed babies gain weight adequately $(81 \%)$ and cow's milk should not be fed to the babies till 1 year of age (77\%). About $62 \%$ of the mothers felt that breast milk should not be stopped when returning to work after maternity leave and switch over to formula feeds. Based on the overall attitude score, $77 \%$ of the study participants had positive attitude towards expression and storage of breast milk. (Table 3)

About $72 \%$ of study participants said that they had expressed breast milk and majority of them have done it manually (95\%). Among them, only $2 \%$ had stored the breast milk before feeding it to the baby. Only $2 \%$ of the study participants had good practices related to expression and storage of breast milk. (Table 4)

The adequate knowledge on EBM was observed and found significantly associated among mothers who were unemployed $(\mathrm{OR}-0.20,95 \% \mathrm{Cl}: 0.07-0.61, \mathrm{p}-0.02)$ and belonged to below middle class (OR $0.18,95 \% \mathrm{Cl}: 0.07-0.45, \mathrm{p}-0.005)$. The positive attitude towards EBM was found among mothers who were aged $>30$ years $(\mathrm{OR}-0.36,95 \% \mathrm{Cl}: 0.19-0.68, \mathrm{p}-0.001)$, educated at high school level and above (OR - 4.51, 95\% Cl: 2.65 - 7.66, p - 0.001), employed mothers (OR - 27.76, 95\% Cl: $9.94-77.45$, $p$ value -0.001$)$, and belonged to middle socio-economic class and above OR $-20.95,95 \% \mathrm{Cl}$ : $10.63-$ $41.29, \mathrm{p}-0.001)$ to be significantly associated.

The good practices towards EBM were found to be associated significantly among mothers who were aged $>30$ years $(\mathrm{OR}-0.56,95 \% \mathrm{Cl}: 0.34-0.93, \mathrm{p}-0.02)$, educated at high school level and above (OR - 3.13, 95\% Cl: 1.88 - 5.22, p- 0.001), employed (OR - 4.10, 95\% Cl: $2.52-6.69, \mathrm{p}-0.001$ ), belonged to middle socio economic class and above (OR $-7.86,95 \% \mathrm{Cl}: 4.86-12.70, \mathrm{p}-0.001)$ and had positive attitude (OR - 14.78, 95\% Cl: $8.52-25.62, \mathrm{p}-0.001)$.

\section{Discussion}

The status of knowledge, attitude, and practice related to the expression and storage of breast milk was studied among 400 mothers who had children aged less than 2 years. In our study, $61.5 \%$ of the study participants were aware of EBM. This was similar to a study done by Monika Lama et.al in Nepal (67.9\%). [5] In our study, $61.5 \%$ of the mothers did not know that breast milk can be expressed and stored. However, the finding from Suvarna et al. in Telangana was controversial, where, it had shown that $68 \%$ of the study participants knew that breast milk can be expressed and stored. ${ }^{[6]}$ The overall knowledge regarding EBM was very low in our study. This was similar to other studies conducted by Ester Mary et al. in Tamilnadu where $91.7 \%$ of the mothers had inadequate knowledge, ${ }^{[7]}$ by Ektha Shinde et al. from Maharashtra 
showed that $68.3 \%$ of the mothers had poor knowledge regarding EBM. ${ }^{[8]}$ Similarly in a study conducted by Attahiru et.al in Nigeria found that most of the respondents (87\%) had poor knowledge regarding EBM. [9]

In our study, $76 \%$ of the study participants had positive attitude towards expression and storage of breast milk. Similar findings were found in a study conducted by Shabbir F et al. in Malaysia (73\%). ${ }^{[10]} \mathrm{Few}$ studies such as Priya Mohan et al. in Maharashtra (57\%) ${ }^{[3]}$, Shrijana Pandey et al. in Nepal $(48 \%)^{[11]}$ reported to have less positive attitude towards EBM.

With regard to practices, in our study only $2 \%$ of the study participants have practiced the technique. The main reason for the respondents not practicing the technique is due to the lack of knowledge and awareness about the importance of breast milk. However there is a high prevalence of feeding expressed breast milk to the babies in developed countries which could be attributed mainly to the organizations which are promoting breast feeding practices in these countries.

Shrijana Pandey et al. found that employed mothers had increased odds of having good knowledge of EBM which was not similar to the present study. ${ }^{[11]}$ In a study conducted by Shabbir $F$ et al. in Malaysia reported that mothers who are well educated are at increased odds of having a positive attitude towards expression and storage of breast milk, however others factors were not significantly associated. ${ }^{[10]}$

The factors which were found to be associated with good practices towards expression and storage of breast milk were age less than 30 years, education, being employed, belonging to middle class and above and the knowledge level of the study participants. However in a study conducted by Attahiru et al. in Nigeria found that there was no association between practice of expressed breast milk and the socio demographic variables. ${ }^{[9]}$

\section{Strength and limitation:}

The exclusive knowledge, attitude and practice towards expressed breastmilk was obtained from the mothers. The recall bias was minimized by including the mothers who had children less than 2 years. Since the study was carried out in a single point of time, the temporal relationship could not be established.

\section{Conclusion}

The overall knowledge and practice regarding EBM was very low, but most of them had positive attitude towards EBM. A positive attitude needs to be transformed into practice regarding the expression and storage of breastmilk. Continued health education for target mother's i.e. antenatal mothers, mothers, working mothers, is required to raise the awareness about EBM. The enhanced knowledge level and positive attitude are essential for the development of favourable practice. 


\section{Declarations}

\section{Ethics approval and consent to participate:}

This study was approved by the Institutional Ethics Committee of Sree Balaji Medical College and Hospital. Written informed consent was obtained from the participants prior to participation. Participants were given rights to withdraw at any time of participation.

\section{Consent for publication:}

All the authors gave consent for publication.

\section{Availability of data and materials:}

Data available on request

\section{Competing interests:}

None

\section{Funding:}

Not applicable

\section{Authors' contributions - Provide individual author's contribution:}

Dr K.R. conceptualized and planned the study and its methodology, collected data and analysed for this article. $\mathrm{DrR} \mathrm{U}$ guided throughout the research work with the expert inputs. Dr M S helped in data analysis and manuscript revision. All the authors read and approved the final manuscript for submission to the journal. This research work is not published or presented elsewhere.

\section{Acknowledgements:}

We would like to thank the college management and the Faculty of Department of Community Medicine for their logistic support and guidance throughout the study. We sincerely thank all the study participants for their valuable time in carrying out this study. We also thank the field staff of UHTC, Anakaputhur for helping to carry out this study by organizing the house visits.

\section{References}

1. World Health Organization. 10 Facts on Breastfeeding. Available from http://www.who.int/features/factfiles/breastfeeding/en/ [Cited 2021 Sep 21].

2. UNICEF for every child. India. Key data [Internet]. [Cited 2021 Sep 17]. Available from: https://www.unicef.org/india/key-data 
3. Prabhu PM, BK R, Naik JD, Brahmankar TR, Bhere VS. Knowledge, Attitude and Practice of

Expression of Breast Milk among Mothers in Western Maharashtra. Journal of Medical Science and Clinical Research. 2016; 04: 8828-34.

4. Khairnar MR, Wadgave U, Shimpi PV. Updated BG Prasad socioeconomic classification for 2016. J Indian Assoc Public Health Dent. 2016; 14: 469-70. [Cited 2021 Sep 18]. Available from: https://www.jiaphd.org/article.asp?issn=23195932; year $=2016$; volume $=14$;issue $=4$; spage $=469$; epage $=470$; aulast $=$ Khairnar

5. Lama M. Working mother's awareness and practice regarding feeding of expressed breast milk. Journal of Patan Academy of Health Sciences. 2019; 6:60-3.

6. Rai S. Expressed breast milk: a less used option by working mothers of India. International Journal of Reproduction, Contraception, Obstetrics and Gynecology. 2017; 6:2874-8.

7. Mary PE. Effectiveness of Self Instructional Module in Knowledge on Collection and Storage of Expressed Breast Milk among Mothers of Infants at Selected Children Hospital in Chennai. International Journal of Health Sciences. 2017:7.

8. Shinde E. Self-instruction module is effective in improving knowledge of mothers regarding expression and storage of breast milk. 2015; 1: 10.

9. Attahiru A, Awosan K, M Oche O, Kaoje AU, Yusuf T, Ango UM. Breastfeeding Support and Determinants of Expressed Breast Milk Feeding Practice among Working Mothers in Sokoto, Nigeria. International Journal of Contemporary Medical Research. 2018; 5.

10. Shabbir F, Nina H, Lim ZT, Amelia AR, Nor Ain Mz, Shaeena I, et al. Expressed Breast Milk Feeding: Knowledge and Attitude of Employed Mothers. Med \& Health. 2020; 15:177-86.

11. Pandey S. Awareness about expressed breast milk feeding among working mothers visiting a tertiary level hospital, Kathmandu. Journal of Kathmandu Medical College. 2020; 8.

\section{Tables}

Table 1: Socio-demographic characteristics of the participants $(N=400)$ 


\begin{tabular}{|c|c|c|c|}
\hline S.No & Characteristic & Number & Percentage \% \\
\hline \multicolumn{4}{|c|}{ 1. Age } \\
\hline & $18-25$ years & 88 & 22 \\
\hline & $26-30$ years & 199 & 49.8 \\
\hline & $31-35$ years & 105 & 26.2 \\
\hline & $36-40$ years & 8 & 2 \\
\hline \multicolumn{4}{|c|}{ 2. Religion } \\
\hline & Hindu & 328 & 82 \\
\hline & Christian & 50 & 12.5 \\
\hline & Others & 22 & 5.5 \\
\hline \multicolumn{4}{|c|}{ 3. Marital status } \\
\hline & Married & 388 & 97 \\
\hline & Divorced & 4 & 2 \\
\hline & Widowed & 8 & 1 \\
\hline \multicolumn{4}{|c|}{ 4. Education } \\
\hline & Illiterate & 2 & 0.5 \\
\hline & Primary and middle school & 76 & 19 \\
\hline & High school and higher secondary & 117 & 29.3 \\
\hline & Graduate and above & 205 & 51.3 \\
\hline \multicolumn{4}{|c|}{ 5. Occupation } \\
\hline & Employed & 173 & 43.3 \\
\hline & Unemployed & 227 & 56.8 \\
\hline \multicolumn{4}{|c|}{ 6. Socio economic status } \\
\hline & Lower & 52 & 13 \\
\hline & Lower middle & 112 & 28 \\
\hline & Middle & 130 & 32.5 \\
\hline & Upper middle & 106 & 26.5 \\
\hline
\end{tabular}


Table 2: Knowledge of the study participants on expression and storage of breast milk $(\mathrm{N}=400)$

\begin{tabular}{|c|c|c|c|}
\hline S.No & Variables & Number & Percentage \% \\
\hline \multicolumn{4}{|c|}{ 1. Have you ever heard of expression and storage of breast milk? } \\
\hline & Yes & 154 & 38.5 \\
\hline & No & 246 & 61.5 \\
\hline \multicolumn{4}{|c|}{ 2. Can the breast milk be pumped and stored and given to the babies? } \\
\hline & Yes & 28 & 7 \\
\hline & No & 306 & 76.5 \\
\hline & Maybe & 66 & 16.5 \\
\hline \multicolumn{4}{|c|}{ 3. Are electric pumps more effective than manual expression? } \\
\hline & Yes & 27 & 6.75 \\
\hline & No & 287 & 71.75 \\
\hline & Maybe & 86 & 21.5 \\
\hline \multicolumn{4}{|c|}{ 4. Can the breast milk be stored at room temperature for 4 to 8 hours? } \\
\hline & Yes & 21 & 5.25 \\
\hline & No & 311 & 77.75 \\
\hline & Maybe & 68 & 17 \\
\hline \multicolumn{4}{|c|}{ 5. Can the breast milk be stored in refrigerator for 3 days? } \\
\hline & Yes & 21 & 5.25 \\
\hline & No & 312 & 78 \\
\hline & Maybe & 67 & 16.75 \\
\hline \multicolumn{4}{|c|}{ 6. Can the breast milk be stored in freezer for 6 months? } \\
\hline & Yes & 21 & 5.25 \\
\hline & No & 310 & 77.5 \\
\hline & Maybe & 69 & 17.25 \\
\hline
\end{tabular}

Table 3: Attitude of the study participants on expression and storage of breast milk $(\mathrm{N}=400)$ 
S.No Attitude towards expression and storage of breast milk

Number

Percentage \%

1. Does expressing breast milk help to return or maintain pre pregnancy weight?

$\begin{array}{lll}\text { Yes } & 40 & 10 \\ \text { No } & 288 & 72 \\ \text { Maybe } & 72 & 18\end{array}$

2. Does pumping increases and maintains mothers' milk production?

$\begin{array}{lll}\text { Yes } & 87 & 21.75 \\ \text { No } & 262 & 65.5 \\ \text { Maybe } & 51 & 12.75\end{array}$

3. Does breast milk fed babies gain weight adequately?

Yes

No

Maybe

4. Cow's milk should not be fed to babies till 1 year of age

Yes

No

Maybe
324

24

52

306

94

76.5

23.5

94

81

6

13

5. Is it best to stop breast milk when we go back to work after maternity leave and switch over to formula feeds?

$\begin{array}{lcc}\text { Yes } & 152 & 38 \\ \text { No } & 248 & 62 \\ \text { Maybe } & - & -\end{array}$

6. Does the taste of the breast milk change after expression and storage?

$\begin{array}{lll}\text { Yes } & 46 & 11.5 \\ \text { No } & 284 & 71 \\ \text { Maybe } & 70 & 17.5\end{array}$

7. Is it too cumbersome to express breast milk?

$\begin{array}{lll}\text { Yes } & 95 & 23.8 \\ \text { No } & 305 & 76.2\end{array}$

Maybe 
8. Does breast milk loses all its nutrition by expression, freezing and thawing?

$\begin{array}{lll}\text { Yes } & 46 & 11.5 \\ \text { No } & 288 & 72 \\ \text { Maybe } & 66 & 16.5\end{array}$

9. The equipment required for expression of breast milk are too expensive when compared to formula feeding?

$\begin{array}{lcc}\text { Yes } & 43 & 10.8 \\ \text { No } & 357 & 89.2\end{array}$

10. Expressing breast milk is more stressful to the mother compared to formula feeding

$\begin{array}{lll}\text { Yes } & 78 & 19.5 \\ \text { No } & 306 & 76.5 \\ \text { Maybe } & 16 & 4\end{array}$

Table 4: Practice of the study participants on expression and storage of breast milk $(\mathrm{N}=400)$

S.No Practice towards expression and storage of breast milk Number Percentage \% 1. Have you ever expressed breast milk?

$\begin{array}{lll}\text { Yes } & 286 & 71.5 \\ \text { No } & 114 & 28.5\end{array}$

2. If yes, how did you express it manually or mechanically?

$\begin{array}{lll}\text { Manual expression } & 271 & 94.7 \\ \text { Mechanical expression } & 15 & 5.3\end{array}$

3. Did you store the breast milk before feeding it to the baby?

$\begin{array}{lll}\text { Yes } & 7 & 2.5 \\ \text { No } & 279 & 97.5\end{array}$

4. If yes, how did you store the milk? 
Table 5: Factors associated with overall knowledge, attitude and practice on expression and storage of breast milk among the study participants 
S.No Variables

1. Knowledge

a. Age (in years)

$\leq 30$
$>30$

b. Education

High school \&above

Below high school

c. Occupation

$$
\text { Employed }
$$

Unemployed

d. Socio economic status

\begin{tabular}{llll} 
Middle class \& above & 6 & 230 & 0.18 \\
\cline { 1 - 3 } Below middle class & 21 & 143 & $(0.07-0.45)$
\end{tabular}

2. Attitude

Positive Negative

Odds Ratio

p-value e
n
n
(95\% Confidence Interval)

\section{a. Age (in years)}

$\begin{array}{llll}\leq 30 & 207 & 80 & 0.36 \\ >30 & 99 & 14 & (0.19-0.68)\end{array}$

b. Education

$\begin{array}{lllll}\text { High school \&above } & 266 & 56 & 4.51 & 0.001 \\ \text { Below high school } & 40 & 38 & (2.65-7.66) & \end{array}$

c. Occupation

$\begin{array}{lllll}\text { Employed } & 169 & 4 & 27.76 & 0.001 \\ \text { Unemployed } & 137 & 90 & (9.94-77.45) & \end{array}$

d. Socio economic status

$\begin{array}{lllll}\text { Middle class \& above } & 225 & 11 & 20.95 & 0.001 \\ \text { Below middle class } & 81 & 83 & (10.63-41.29) & \end{array}$

e. Practice level 


\begin{tabular}{|c|c|c|c|c|c|}
\hline & Good & 253 & 22 & \multirow{2}{*}{$\begin{array}{l}15.62 \\
(8.90-27.4)\end{array}$} & \multirow[t]{2}{*}{0.001} \\
\hline & Bad & 53 & 72 & & \\
\hline \multirow[t]{2}{*}{3.} & Practices & Good & Poor & Odds Ratio & p-value \\
\hline & & $\mathbf{n}$ & $\mathrm{n}$ & (95\% Confidence Interval) & \\
\hline \multicolumn{6}{|c|}{ a. Age (in years) } \\
\hline & $\leq 30$ & 188 & 99 & \multirow{2}{*}{$\begin{array}{l}0.56 \\
(0.34-0.93)\end{array}$} & \multirow[t]{2}{*}{0.02} \\
\hline & $>30$ & 87 & 26 & & \\
\hline \multicolumn{6}{|c|}{ b. Education } \\
\hline & High school and above & 238 & 84 & \multirow{2}{*}{$\begin{array}{l}3.13 \\
(1.88-5.22)\end{array}$} & \multirow[t]{2}{*}{0.001} \\
\hline & Below high school & 37 & 41 & & \\
\hline \multicolumn{6}{|c|}{ c. Occupation } \\
\hline & Employed & 146 & 27 & \multirow{2}{*}{$\begin{array}{l}4.10 \\
(2.52-6.69)\end{array}$} & \multirow[t]{2}{*}{0.001} \\
\hline & Unemployed & 129 & 98 & & \\
\hline \multicolumn{6}{|c|}{ d. Socio economic status } \\
\hline & Middle class and above & 203 & 33 & \multirow{2}{*}{$\begin{array}{l}7.86 \\
(4.86-12.70)\end{array}$} & \multirow[t]{2}{*}{0.001} \\
\hline & Below middle class & 72 & 92 & & \\
\hline \multicolumn{6}{|c|}{ e. Attitude Level } \\
\hline & Adequate & 68 & 46 & \multirow{2}{*}{$\begin{array}{l}14.78 \\
(8.52-25.62)\end{array}$} & \multirow[t]{2}{*}{0.001} \\
\hline & Inadequate & 26 & 260 & & \\
\hline
\end{tabular}

